\title{
PROJETOS DE CONTROLADORES ROBUSTOS PARA UM SISTEMA LEVITADOR MAGNÉTICO.
}

\author{
Ian da Silva Viganó ${ }^{1}$; Márcia Lissandra Machado Prado² \\ 1. Bolsista PIBIC/FAPESB, Graduando em Engenharia de Computação, Universidade Estadual de Feira de Santana, \\ e-mail: $\underline{\text { ians028@gmail.com }}$ \\ 2. Orientador, Departamento de tecnologia, Universidade Estadual de Feira de Santana, e-mail: \\ marcia.lissandra@gmail.com
}

PALAVRAS-CHAVE: Teoria de Controle, Controle Robusto, Sistema Levitador Magnético

\section{INTRODUÇÃO}

Os Sistemas de Controle têm desempenhado um papel fundamental na evolução da engenharia e da ciência. Exemplos de sua importância estão nos sistemas de veículos espaciais, sistemas de controle de mísseis, sistemas robóticos e similares, sistemas de controle de pressão, velocidade, temperatura, vazão, etc (Ogata, 2010).

Uma área da tecnologia que atualmente envolve uma grande linha de pesquisa são os sistemas de levitação magnética, que é o processo com o qual se consegue suspender um objeto numa posição estável, contrariando, assim, as forças de gravidade, mediante o uso de forças exercidas sem contato com o objeto. Manter um corpo suspenso no ar, sem qualquer apoio aparente, como que desafiando a lei da gravidade, é reconhecido como fenômeno de levitação (Barbosa et al., 2004).

Este trabalho propõe a aplicação da metodologia de análise intervalar modal descrita em (Prado e Paz, 2008) no projeto de controladores robustos. Para isso foram aplicadas variações nos parâmetros do sistema, gerando, assim, intervalos modais. A substituição dos parâmetros constantes do sistema por intervalos permite tornar os parâmetros do sistema variáveis e, com isso, fazendo uso da aritmética intervalar modal (Sainz et al, 2014), é possível realizar o projeto do controlador robusto.

\section{MATERIAL E MÉTODOS OU METODOLOGIA (ou equivalente)}

Para realizar a modelagem do sistema são usadas as equações diferenciais que podem representar a dinâmica do sistema matematicamente (Dorf e Bishop, 2001). O sistema do Levitador Magnético pode ser dividido em dois subsistemas, o elétrico e o eletromecânico, onde a saída do sistema elétrico serve de entrada para o sistema eletromecânico. Esses sistemas podem ser modelados separadamente. Essa abordagem foi utilizada e as sub-plantas e seus respectivos controladores são apresentados separadamente. Para a parte elétrica do sistema são usadas as leis de Kirchhoff para definir relações entre as tensões e/ou correntes no sistema. A bobina usada no eletroímã tem uma indutância e uma resistência, assim, utilizando as equações diferenciais, a $2^{\circ}$ lei de Kirchhoff, a Lei de Ohm, a Lei da indutância de Faraday e a transformada de Laplace obtemos a seguinte função de transferência para o subsistema elétrico: 
Onde $\mathrm{A}=2,42$ e $\mathrm{B}=26,6$.

$$
\begin{gathered}
G_{e}(s)=\frac{A}{s+B} \\
\text { Equação } 1
\end{gathered}
$$

De forma análoga fazemos o mesmo processo para o subsistema eletromecânico utilizando as leis de Newton obtemos:

$$
\begin{gathered}
G_{m}(s)=\frac{C}{s^{2}-D} \\
\text { Equação } 2
\end{gathered}
$$

$\operatorname{com} \mathrm{C}=-19600$ e $\mathrm{D}=2800$.

Para o projeto dos controladores partiu-se da equação de realimentação em malha fechada dada por:

$$
G m f(s)=\frac{C(s) G(s)}{1+C(s) G(s)}
$$

Equação 3

Onde $C(s)$ representa a função de transferência do controlador e $G(s)$ é a função de transferência que representa o comportamento dinâmico da planta. Desenvolvendo essa equação para ambos os subsistemas, e utilizando um controlador PID (Proporcional-Integral-Derivativo), dada por, $C(s)=\frac{K d s^{2}+K p s+K i}{s}$ obtemos:

$$
\begin{aligned}
& G m f_{c}(s)= \frac{A(K p d+K d s+K i)}{(A K d+1) s^{2}+(A K p R+B) s+A K i R} \\
& G m f_{m}(s)= \frac{C \text { Equação } 4}{s^{3}+C K d s^{2}+(C K p+D) s+C K i H} \\
& \text { Equação } 5
\end{aligned}
$$

Nas equações (4) e (5) R e H, são respectivamente, uma resistência e um conversor de um sinal de posição para um sinal de corrente, pois como nos subsistemas os sinais de entrada não tem a mesma unidade dos sinais de saída, se faz necessário esse tipo de conversão para a realimentação da planta. Para o subsistema elétrico o conversor é uma simples resistência que relaciona diretamente a tensão (entrada) com a corrente (saída), Já para o subsistema eletromecânico H é uma função que relaciona a corrente (entrada) com a posição (saída).

Para encontrar os ganhos do controlador PID é necessário comparar o denominador da equação (4) com a equação (6) que representa a equação padrão de segunda ordem. Dessa forma é possível determinar os valores dos ganhos em função dos parâmetros de desempenho definidos para o sistema, da mesma forma é feito para a equação (5), porém comparando seu denominador com a equação (7), que é o sistema padrão de terceira ordem.

$$
\begin{gathered}
s^{2}+2 \varepsilon \omega_{n}+\omega_{n}{ }^{2} \\
\text { Equação } 6
\end{gathered}
$$




$$
\begin{gathered}
s^{3}+\left(p+2 \varepsilon \omega_{n}\right) s^{2}+\left(2 p \varepsilon \omega_{n}+{\omega_{n}}^{2}\right) s+p \omega_{n}{ }^{2} \\
\text { Equação } 7
\end{gathered}
$$

Os parâmetros de desempenho definidos para a planta foram $10 \%$ de sobre-elevação máxima e um tempo de acomodação de $0.15 \mathrm{~s}$. Esses parâmetros de desempenho resultam em um $\varepsilon=0,59$ e um $\omega_{n}=33,89$.

Para projetar o controlador robusto os parâmetros, tanto da planta, quanto de desempenho do projeto foram variados em $10 \%$. Com isso os valores de A,B,C,D, $\varepsilon$ e $\omega_{n}$ se tornam intervalos, com o valor desses intervalos e aplicando a aritmética intervalar descrita em (Saintz et al, 2014) obtemos o valor para os ganhos do controlador na forma de intervalos, são eles: $[K d]^{\prime}=0,[K p]^{\prime}=[5.70420,5.70523] e$ $[K i]^{\prime}=[498.55,467.22]$ para o subsistema elétrico e $[K d]^{\prime}=[-0,0040 ;-0,0054]$, $[K p]^{\prime}=[-0,2887 ;-0,3265]$ e $\left[K_{i j}^{\prime}=[-0,0234 ;-0,0372]\right.$ para o subsistema eletromecânico.

\section{RESULTADOS E/OU DISCUSSÃO (ou Análise e discussão dos resultados)}

Para analisar o controlador proposto, este foi aplicado na planta, por simulação, com parâmetros variáveis, fazendo o sistema resultante responder ao degrau unitário. Os valores de parâmetros da planta (A e B) foram variados de forma a representar os dois extremos dos seus respectivos intervalos, o ponto médio, uma média entre o ponto mínimo e o ponto médio, chamada de Média inferior, e uma média entre o ponto médio e o ponto máximo, chamada de Média superior, esses valores podem ser vistos na Tabela 1. Os valores de $K p$ e $K i$ foram variados em um conjunto de dez controladores dentro dos intervalos e aplicados a cada uma das variações da planta.

\begin{tabular}{|c|c|c|c|c|}
\hline & A & B & C & D \\
\hline Ponto mínimo & 2,178 & 23,94 & -17640 & 2520 \\
\hline Média inferior & 2,299 & 25,27 & -18620 & 2660 \\
\hline Ponto médio & 2,420 & 26,60 & -19600 & 2800 \\
\hline Média superior & $\mathbf{2 , 5 4 1}$ & 27,93 & -20570 & 2940 \\
\hline Ponto máximo & $\mathbf{2 , 6 6 2}$ & $\mathbf{2 9 , 2 6}$ & -21560 & $\mathbf{3 0 8 0}$ \\
\hline
\end{tabular}

Tabela 1: Parâmetros do variados referente ao subsistema elétrico e eletromecânico

A Figura 3-A mostra o resultado obtido para o subsistema elétrico do levitador magnético, onde foram aplicados os valores de $K p$ e $K i$ na equação (4). É possível perceber através da análise do gráfico que o erro de regime foi eliminado e que o sistema atende aos requisitos propostos para todas as variações dos controladores aplicados (dentro dos intervalos definidos por $K p$ e $K i$, a cada uma das variações aplicadas sobre a planta original, mantendo sobre-elevação máxima inferior a $11 \% \mathrm{e}$ tempo de estabelecimento menor que 0.165 segundos (com critério de 5\%), que são os valores máximos aceitos após a variação de $10 \%$ sobre os requisitos de projeto. No gráfico apresentado e nos que vem a seguir, Médial corresponde à Média inferior e Média2 corresponde a Média superior e seus valores correspondentes estão na Tabela 1. 

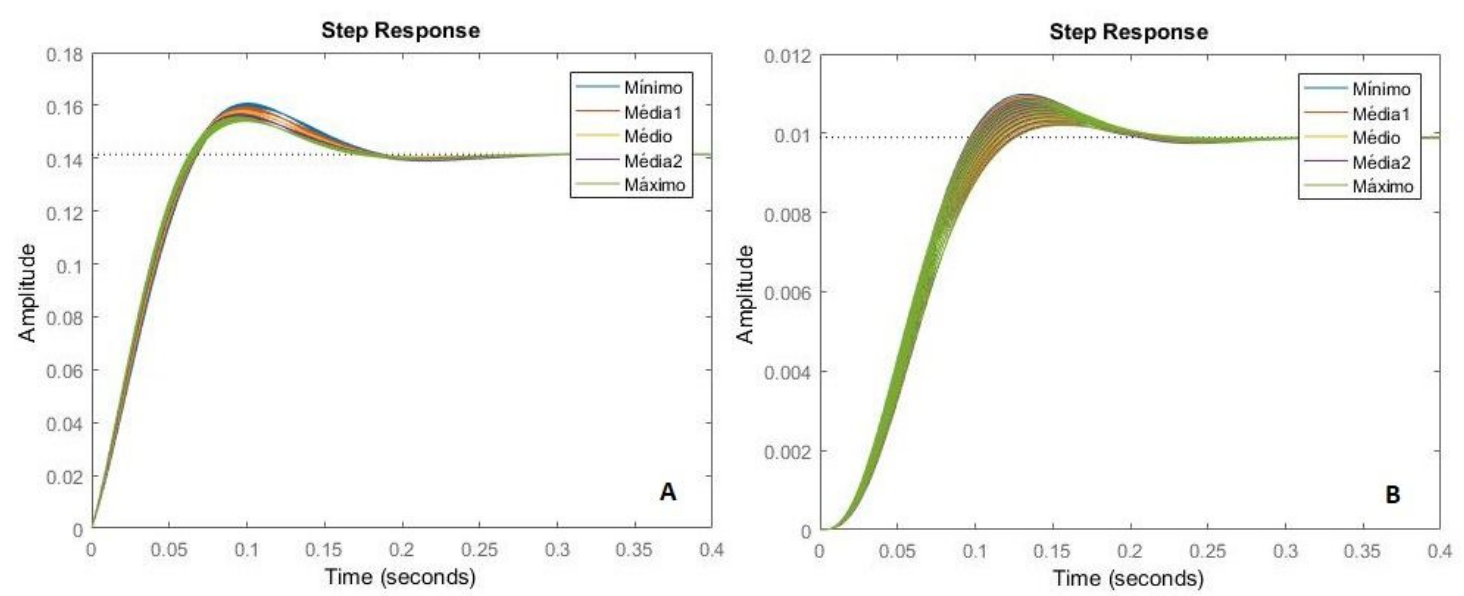

Figura 3: A - Resposta ao degrau do subsistema elétrico. B - Resposta ao degrau do subsistema elétrico e eletromecânico.

A Figura 3-B mostra a resposta ao degrau obtido para o subsistema eletromecânico do levitador magnético, onde foram aplicados os valores de $K d, K p$ e $K i$ na equação (5). É possível perceber através da análise do gráfico que o erro de regime foi eliminado e que o sistema atende aos requisitos propostos para todas as variações dos controladores aplicados (dentro dos intervalos definidos por $K d, K p$ e $K i$, a cada uma das variações aplicadas sobre a planta original, mantendo sobre-elevação máxima inferior a $11 \% \mathrm{e}$ tempo de estabelecimento menor que 0.165 segundos (com critério de $5 \%$ ), que são os valores pretendidos de desempenho após a variação de $10 \%$ sobre os requisitos de projeto.

\section{CONSIDERAÇÕES FINAIS (ou Conclusão)}

Através da análise dos resultados obtidos com o projeto do controlador robusto foi possível perceber que o sistema atende todos as especificações do projeto, eliminando o erro de regime permanente e com um tempo de resposta dentro do limite estipulado. Constatou-se ainda que o sinal de controle assumiu valores ótimos dentro do esperado.

\section{REFERÊNCIAS}

BARBOSA, L. F. W; COSTA, F; LUDWIG, G. O; NASCIMENTO JR, C. L. 2004. Controle analógico de um levitador magnético (maglev) de simples construção e operação, XV Brazilian Conference on Automatics, Gramado, Brazil.

DORF, R. C; BISHOP, R. H. 2001. Sistemas de Controle Modernos.

OGATA, K. (2010). Engenharia de Controle Moderno, Pearson. 5ed. 824p.

PRADO, M; PAZ, M. (2008). Controle robusto utilizando estrutura pd e análise intervalar modal, XIII Congresso Latinoamericano de Control Automático, Mérida.

SAINZ, M. A; ARMENGOL, J; CALM, R; HERRERO, P; JORBA, L; VEHI, J. (2014). Modal interval analysis, Lecture Notes in Mathematics 2091. 